\title{
Genetic inactivation of the LIGHT (TNFSF14) cytokine in mice restores glucose homeostasis and diminishes hepatic steatosis
}

\author{
Andrea Herrero-Cervera ${ }^{1}$ • Ángela Vinué ${ }^{1}$ • Deborah J. Burks ${ }^{2,3}$ • Herminia González-Navarro ${ }^{1,3,4}$
}

Received: 17 December 2018 / Accepted: 10 June 2019 / Published online: 6 August 2019

(C) Springer-Verlag GmbH Germany, part of Springer Nature 2019

\begin{abstract}
Aims/hypothesis Non-alcoholic fatty liver disease (NAFLD) is frequently associated with type 2 diabetes mellitus. Progression of NAFLD is mediated, among other things, by activation of inflammatory pathways. In the present study, the role of the proinflammatory cytokine LIGHT (TNFSF14) was explored in NAFLD and type 2 diabetes mellitus in mice deficient for the cytokine.

Methods Light-deficient $\left(\right.$ Light $\left.^{-/}\right)$mice and WT controls were fed a regular chow diet (RCD) or a high-fat high-cholesterol diet (HFHCD) for 16 weeks. The expression of LIGHT and its receptors, herpes virus entry mediator (HVEM) and lymphotoxin $\beta$ receptor (LT $\beta$ R), was investigated in both dietary regimens. Glucose tolerance, insulin sensitivity, non-alcoholic fatty liver (NAFL), systemic and tissue inflammation, and metabolic gene expression were explored in $\mathrm{Light}^{-{ }^{-}}$and WT mice fed an RCD and an HFHCD. The effect of Light deficiency was also evaluated in hepatic tissue and in inflammation in HFHCD-fed $I r s 2^{+/}$mice with impaired insulin signalling.

Results Light deficiency did not have an effect on metabolism, in NAFL or in tissue and systemic inflammation, in RCD-fed WT mice. HVEM and LT $\beta R$ were markedly increased in livers of HFHCD-fed WT mice compared with RCD-fed WT controls. In WT mice under HFHCD, Light deficiency improved glucose tolerance and insulin sensitivity. Non-alcoholic fatty liver disease activity (NAS) score, hepatic $\mathrm{CD}^{+} \mathrm{T}$ lymphocytes and F4/80 $0^{+}$macrophages were decreased in HFHCD-fed ight $^{-/}$mice compared with HFHCD-fed WT controls. Consistent with a potential role of adipose tissue in hepatic homeostasis, Light $^{-/}$mice exhibited augmented anti-inflammatory $\mathrm{F} 4 / 80^{+} \mathrm{CD} 206^{+}$adipose tissue macrophages and reduced proinflammatory $\mathrm{F} 4 /$ $80^{+} \mathrm{CD} 11 \mathrm{c}^{+}$adipose tissue macrophages. Moreover, adipose tissue explants from $\mathrm{Light}^{-/}$mice showed diminished secretion of monocyte chemoattractant protein 1 (MCP1), TNF- $\alpha$ and IL-17 cytokines. Circulating Light $^{-/}$leucocytes consistently displayed augmented levels of the patrolling Ly6 $\mathrm{C}^{\mathrm{low}}$ monocytes, decreased Th9 T cell subset and diminished plasma TNF- $\alpha$ and IL-6 levels. Similarly, Light deficiency in Irs $2^{+/}$mice, which display impaired insulin signalling, also reduced NAFL as well as systemic and adipose tissue inflammation. Analysis of hepatic gene expression in $\mathrm{Light}^{-1-}$ mouse livers showed reduced levels of Zbtb16, the transcription factor essential for natural killer T (NKT) cell function, and two genes related to NAFLD and fibrosis, Klf6 and Tlr4.

Conclusions/interpretation These results indicate that Light deficiency in HFHCD improves hepatic glucose tolerance, and reduces hepatic inflammation and NAFL. This is accompanied by decreased systemic inflammation and adipose tissue cytokine secretion and by changes in the expression of key genes such as Klf6 and Tlr4 involved in NAFLD. These results suggest that therapies to block LIGHT-dependent signalling might be useful to restore hepatic homeostasis and to restrain NAFLD.
\end{abstract}

Keywords Adipose tissue · Glucose intolerance $\cdot$ Hepatic steatosis · Insulin resistance $\cdot$ LIGHT (TNFSF14) · Metabolism

Electronic supplementary material The online version of this article (https://doi.org/10.1007/s00125-019-4962-6) contains peer-reviewed but unedited supplementary material, which is available to authorised users.

Herminia González-Navarro

herminia.gonzalez@uv.es

1 INCLIVA Health Research Institute, Avda. Menéndez Pelayo, 4, 46010 Valencia, Spain

2 The Prince Felipe Research Center (CIPF), Valencia, Spain
3 CIBER Diabetes and Associated Metabolic Diseases (CIBERDEM), Madrid, Spain

4 Department of Didactics of Experimental and Social Sciences, University of Valencia, Valencia, Spain 


\section{Research in context}

What is already known about this subject?

- Hepatic inflammation promotes the development of non-alcoholic fatty liver disease (NAFLD)

- $\quad$ LIGHT (TNFSF14) is a proinflammatory cytokine increased in individuals with NAFLD and type 2 diabetes mellitus

- Cholesterol-rich diets and insulin resistance are both factors that predispose to NAFL-to-NASH (non-alcoholic steatohepatitis) transition

What is the key question?

- Does LIGHT modulate carbohydrate metabolism and progression of NAFLD in a cholesterol-rich diet?

What are the new findings?

- A high-fat high-cholesterol diet (HFHCD) in WT mice promotes hepatic LIGHT/LTßR-HVEM-mediated signalling by increasing receptor expression

- Light deficiency in HFHCD-fed mice improves glucose tolerance, insulin sensitivity and NAFL, and reduces hepatic, adipose tissue and systemic inflammation

- Light deficiency decreases hepatic expression of genes associated with the NAFL-to-NASH transition, such as KIf6 and TIr4

How might this impact on clinical practice in the foreseeable future?

- Modulation of LIGHT-dependent signalling might be a therapeutic avenue to reduce the transition of NAFL to NASH associated with insulin resistance

$\begin{array}{ll}\text { Abbreviations } \\ \text { ALT } & \text { Alanine aminotransferase } \\ \text { AST } & \text { Aspartate aminotransferase } \\ \text { ATM } & \text { Adipose tissue macrophage } \\ \text { CCR } & \text { C-C chemokine receptor } \\ \text { CXCR } & \text { CXC chemokine receptor } \\ \text { HCC } & \text { Hepatocellular carcinoma } \\ \text { HFHCD } & \text { High-fat high-cholesterol diet } \\ \text { HVEM } & \text { Herpes virus entry mediator } \\ \text { LIGHT } & \text { Homologous to Lymphotoxin, exhibits Inducible } \\ & \text { expres s i on and co mpete s with HS V } \\ & \text { Glycoprotein D for binding to Herpesvirus entry } \\ & \text { mediator, a receptor expressed on T lymphocytes } \\ \text { LT } \beta R & \text { Lymphotoxin } \beta \text { receptor } \\ \text { MCP1 } & \text { Monocyte chemoattractant protein 1 } \\ \text { NAFL } & \text { Non-alcoholic fatty liver } \\ \text { NAFLD } & \text { Non-alcoholic fatty liver disease } \\ \text { NAS } & \text { Non-alcoholic fatty liver disease activity (score) } \\ \text { NASH } & \text { Non-alcoholic steatohepatitis } \\ \text { NKT } & \text { Natural killer T } \\ \text { RCD } & \text { Regular chow diet } \\ \text { Th } & \text { T helper } \\ \text { TNFSF14 } & \text { TNF superfamily member 14 } \\ \text { SVF } & \text { Stromal vascular fraction } \\ \text { WT } & \text { Wild-type } \\ \end{array}$

\section{Introduction}

Non-alcoholic fatty liver disease (NAFLD) is a major metabolic complication frequently associated with insulin resistance, a key feature of type 2 diabetes mellitus. Both of these metabolic alterations are becoming health problems due to the increasing obesity and sedentary lifestyle patterns in the population, which predispose to these pathologies [1].

Remarkably, NAFLD develops in up to $90 \%$ of obese and up to $70 \%$ of overweight people [2]. The excess of fat in adipose tissue and adipocyte hypertrophy activate NEFA release which accumulates in the liver, promoting non-alcoholic fatty liver (NAFL) [3]. Moreover, sustained adipose tissue expansion might activate stress-induced mitogen-activated protein kinases, generating adipose tissue dysfunction and promoting the release of proinflammatory cytokines into the bloodstream which facilitate inflammation-induced insulin resistance and NAFL. While NAFL is asymptomatic per se, hepatic inflammation induces the transition to non-alcoholic steatohepatitis (NASH), a hepatic dysfunctional metabolic state. Interestingly, some studies in humans indicate that NASH might even develop before steatosis in some cases such as hepatic cholesterol accumulation [4], which induces inflammation and hepatic uptake of fatty acids. Current hypotheses on the NAFL-to-NASH transition involve many 
factors such as defective insulin signalling, characteristic of insulin resistance, genetic predisposition and environmental factors such as cholesterol-enriched diets [5, 6].

LIGHT (TNFSF14) (Homologous to Lymphotoxin, exhibits Inducible expression and competes with HSV Glycoprotein D for binding to Herpesvirus entry mediator, a receptor expressed on T lymphocytes [TNF superfamily member 14]) is a soluble inflammatory cytokine that belongs to the TNF superfamily of proinflammatory molecules [7]. LIGHT is mainly produced by $\mathrm{T}$ cells and monocytes, and mediates its effects through three receptors, the lymphotoxin $\beta$ receptor (LT $\beta-R)$, the herpes virus entry mediator (HVEM) and decoy receptor 3 (DcR3) which inhibits its function [8]. Previous studies have shown that LIGHT-deficient macrophages display reduced production of cytokines [7], while constitutive overexpression of LIGHT promotes T lymphocyte activation and maturation and leads to severe inflammation and tissue destruction [9]. A role for LIGHT has also been suggested in hepatic homeostasis since investigations in humans associate enhanced levels of the cytokine with NAFLD [10], with insulin resistance and the metabolic syndrome [11], and with type 2 diabetes mellitus [12]. These studies suggest a function of LIGHT in the development of liver dysfunction-related diseases.

In the present study, we investigated whether genetic inactivation of LIGHT modulates hepatic metabolic diseases, insulin resistance and NALFD, and potential underlying molecular mechanisms. To this end, metabolism, inflammation and hepatic derangement were investigated in $\mathrm{Light}^{-/-}$and wildtype (WT) mice fed a regular chow $\operatorname{diet}(\mathrm{RCD})$ and a high-fat high-cholesterol diet (HFHCD) for 16 weeks (NB Light is also known as Tnfsf14). In addition, studies were also performed in $\operatorname{Irs} 2^{+/}$mice, which display impaired insulin signalling [13].

\section{Methods}

Generation of mice, diets and treatments The experimental (Light $^{-/} n=46$ and $\mathrm{Irs}^{+/-} \mathrm{Light}^{-/-} n=21$ ) and control groups (WT $=36$ and $\operatorname{Irs} 2^{+/-} n=26$ ) were generated by crosses between WT, $\mathrm{Light}^{-/}$and $\mathrm{IrS}^{+2^{+-}}$mice at INCLIVA animal facility (all in C57BL/6J background). Mice had free access to water, and were under temperature- and humiditycontrolled conditions $\left(22 \pm 1{ }^{\circ} \mathrm{C}, 40-45 \%\right)$ with $12 \mathrm{~h} \mathrm{light/dark}$ cycles in a conventional animal facility. Mice were maintained on an RCD (2.8\% fat; Panlab, Barcelona, Spain) and at 8 weeks of age were randomly placed on an HFHCD (10.8\% fat, $0.75 \%$ cholesterol; S4892-E010, Ssniff, Soest, Germany) or left on an RCD for 16 more weeks. Analysis was performed in male and female mice. Animal procedures were approved by the Animal Ethics Committee of INCLIVA and followed the 2010/63/EU directive from the European Parliament.
Plasma measurements, body and liver weight and fat mass distribution, and metabolic studies Biochemical determinations were performed in isolated plasma from whole blood in the presence of EDTA from overnight-fasted mice. Analysis included triacylglycerol, total cholesterol, ApoBcholesterol, HDL-cholesterol [14], alanine aminotransferase (ALT) and aspartate aminotransferase (AST) activities following the indicated protocols. GTTs and ITTs [15] were performed in overnight- and $4 \mathrm{~h}$-fasted mice, respectively, and glucose and insulin levels were measured as reported [16]. For liver weight and body fat mass distribution, liver and inguinal, epididymal and mesenteric fat pads were dissected from mouse bodies, weighed and expressed as percentage of total body weight. See electronic supplementary material (ESM) Methods.

Hepatic triacylglycerol content Triacylglycerol hepatic content was determined by tissue digestion and saponification in ethanolic potassium hydroxide [17], followed by an enzymatic measurement of glycerol content (Free Glycerol Reagent, Sigma, St Louis, MO, USA).

Western blot analysis Protein extracts were obtained by homogenising snap-frozen liver and adipose tissue as described [18] and prepared for immunoblot analysis using specific primary antibodies, anti-LT $\beta$ R, anti-HVEM and anti- $\beta$ actin, followed by secondary horseradish peroxidase (HRP)conjugated antibodies and detected by chemiluminescence. See electronic supplementary material (ESM) Methods.

Immunohistopathological characterisation of liver Livers were sectioned from mice, washed with PBS, fixed with $4 \%$ paraformaldehyde/PBS and paraffin embedded [13, 18]. Hepatic macrophage content was determined by anti-F4/80 marker immunohistochemistry [13]. For CD3, F4/80-LT $\beta R$, F4/80-HVEM and F4/80-LIGHT immunofluorescences, cross-sections were treated for antigen retrieval and incubated with primary antibodies followed by fluorescent secondary antibody [15]. Liver complications were assessed by steatosis, hepatocellular ballooning, lobular inflammation and nonalcoholic fatty liver disease activity (NAS) score in haematoxylin-eosin-stained sections and fibrosis in Masson trichrome-stained sections [19]. See electronic supplementary material (ESM) Methods.

Flow cytometry analysis of stromal vascular fraction cells from adipose tissue Stromal vascular fraction (SVF) cells were isolated by digestion of epididymal fat pads with $1 \mathrm{mg} / \mathrm{ml}$ type I collagenase (Worthington, Lakewood, NJ, USA) at $37^{\circ} \mathrm{C}$ for $30 \mathrm{~min}$. SVF cells were washed, fixed with Zombie Aqua fixable viability kit (BioLegend, San Diego, CA, USA) and stained (30 min at room temperature) with anti-mouse F4/80-APC (MCA497APTC, Bio-Rad, Hercules, 
CA, USA), anti-mouse CD11c-PE (12-0114-81, eBioscience, San Diego, CA, USA) and anti-mouse CD206-AlexaFluor488 (MCA2235A488T, Bio-Rad). Stains were followed by incubation with FACS lysing solution for 15-20 min and flow cytometry analysis using FACSVerse (BD Biosciences, San Jose, CA, USA) to determine proinflammatory M1 F4/ $80^{+} \mathrm{CD} 11 \mathrm{c}^{+} \mathrm{CD} 206^{-}$adipose tissue macrophages (ATMs) and alternative $\mathrm{M} 2 \mathrm{~F} 4 / 80^{+} \mathrm{CD} 11 \mathrm{c}^{-} \mathrm{CD} 206^{+}$ATMs.

ELISA Circulating levels of cytokines were determined in isolated plasma from heparinised mouse blood (10 U heparin/ml) obtained from different mice using the specific cytokine DuoSEt ELISA kits (R\&D Systems, Minneapolis, MN, USA).

Circulating leucocyte analysis by flow cytometry To characterise circulating leucocytes, $10 \mu \mathrm{l}$ heparinised whole blood was incubated for $30 \mathrm{~min}$ at room temperature with CD45FITC, Ly6C-PerCP (553080 and 560525, BD Pharmingen, Franklin Lakes, NJ, USA) and CD115-APC (135509, BioLegend) for monocyte analysis. For identification of $\mathrm{T}$ helper (Th) cell subsets in mice, the human protocol was adapted for mouse blood as described [20, 21]. Mouse blood was also incubated (30 min, room temperature) with BV421C-C chemokine receptor (CCR)4 (CD194) (131217, BioLegend), CD4-FITC (130-102-541, Miltenyi, Bergisch Gladbach, Germany), CXC chemokine receptor (CXCR)3 (CD183)-APC (17-1831-80, eBioscience) and CCR6(CD196)-PEVio770 (130-103-818, Miltenyi). Stains were followed by incubation with FACS lysing solution (BD Biosciences) for 15-20 min before flow cytometry analysis using FACSVerse or Fortessa Flow cytometers (BD Biosciences).

Adipose tissue explant isolation Epididymal fat pads were minced into $2-3 \mathrm{~mm}^{3}$ and incubated for $24 \mathrm{~h}$ at $100 \mathrm{mg} / \mathrm{ml}$ in six-well plates with DMEM-P/S/A-10\%FBS medium in a humidified 5\% $\mathrm{CO}_{2}$ atmosphere. Explants were washed with PBS1X twice and incubated with DMEM-P/S/A-0.1\%FBS medium for $24 \mathrm{~h}$, and the medium was collected for cytokine analysis by ELISA.

Experiments with bone marrow-derived macrophages Cells from femoral bone marrow were cultured at $1 \times 10^{6}$ cells $/ \mathrm{ml}$ density and differentiated over 7 days [15], then incubated for $24 \mathrm{~h}$ with serum-free medium for cytokine secretion analysis. See electronic supplementary material (ESM) Methods.

\section{Gene expression analysis by quantitative real-time PCR RNA} $(0.5-1 \mu \mathrm{g})$ from mouse tissues was obtained using TRIzol reagent (Invitrogen, Carlsbad, CA, USA), reversetranscribed with the Maxima First-Strand kit and amplified with Luminaris Color qPCR MasterMIX (Fermentas,
Waltham, MA, USA) on a 7900 FastSystem thermal cycler. Results were analysed with the provided software (Applied Biosystems, Foster city, CA, USA). mRNA levels were normalised to the cyclophilin expression and relativised to controls. The primer sequences can be found in ESM Table 1.

Statistical analysis Quantitative variables are shown as single data points and mean $\pm \mathrm{SEM}$. Mouse sample replicates for in vivo data were obtained from individual mice. For adipose tissue and macrophage experiments, replicates were obtained from 4-6 samples derived from three or two independent mice per genotype. All data obtained were analysed by observers blinded to genotype and the criteria for exclusion were data out of range of the standard curve or samples that were lost during the experiment. Data were analysed for normal distribution using D'Agostino-Pearson omnibus test. Differences were evaluated with Student's $t$ test (two groups, paired test), Mann-Whitney $U$ test (nonparametric test), one-way ANOVA followed by Bonferroni multiple comparison test (more than two mouse groups) and two-way ANOVA followed by Tukey's post hoc multiple comparison test (two mouse groups and two treatments) (GraphPad Prism Software, La Jolla, CA, USA). Statistical significance was set at $p \leq 0.05$. Male and female data were displayed together, and when sex-dependent responses were observed data were presented separately.

\section{Results}

HFHCD increases LT $\beta$ R and HVEM expression in WT mice To evaluate the impact of HFHCD on LIGHT-mediated signalling in WT mice, circulating LIGHT levels and expression of LT $\beta$ R and HVEM receptors in liver and adipose tissue were explored. Circulating LIGHT levels were similar between RCD- and HFHCD-fed WT mice (Fig. 1a). mRNA expression analysis showed enhanced levels of Light in liver in HFHCDfed WT mice (Fig. 1b) but no changes in adipose tissue gene expression (Fig. 1c). Protein expression analysis of LIGHT receptors revealed augmented hepatic and adipose tissue levels of LT $\beta$ R and HVEM (Fig. 1d-i) in HFHCD-fed WT mice compared with RCD-fed WT controls. Double immunofluorescences of LIGHT, LT $\beta$ R and HVEM with F4/80 macrophage marker showed most of the receptor expression in parenchymal hepatic cells (Fig. 1j, k), while LIGHT levels were low and localised in macrophages as well as in other cell types (Fig. 11). These data indicate that HFHCD feeding induces an increase in the LIGHT/LT $\beta$ R-HVEM-dependent signalling.

Light deficiency improves glucose tolerance, insulin sensitivity and NAFLD in WT mice fed HFHCD Analysis of mice fed an RCD did not show differences in body weight, fat mass content or distribution between $\mathrm{Light}^{-/}$and WT mice or in liver 
Fig. 1 LIGHT/LT $\beta R-H V E M$ expression analysis in liver and adipose tissue from WT mice fed an RCD and an HFHCD. (a) Circulating plasma levels of LIGHT in mice fed an RCD and an HFHCD. mRNA levels of Light in (b) liver and (c) adipose tissue. Protein levels of $(\mathbf{d}, \mathbf{g})$ LT $\beta R$ and $(\mathbf{e}, \mathbf{h})$ HVEM in liver (d-f) and adipose tissue ( $\mathbf{g}-\mathbf{i})$ homogenates in RCD-fed and HFHCD-fed WT mice. (f, i) Representative blots showing LT $\beta R$ and HVEM levels in (f) liver and (i) adipose tissue. Double immunofluorescence of (j) F4/80-LT $\beta R$, (k) F4/80HVEM and (l) F4/80-LIGHT in WT mice fed an RCD and an HFHCD. Triangles, RCD-fed mice; circles, HFHCD-fed mice; white, male WT mice; grey, female WT mice. Scale bars, $50 \mu \mathrm{m}$, and $20 \mu \mathrm{m}$ in the magnifications. mRNA levels were normalised to endogenous cyclophilin expression and are relative to RCD-fed mouse levels. Total protein levels were normalised to $\beta$-actin. Data are shown as individual data points with mean \pm SEM. Statistical analysis was performed using Student's $t$ test $(* p<0.05$, $* * p<0.01$ and $* * * p<0.001)$. AT, adipose tissue a

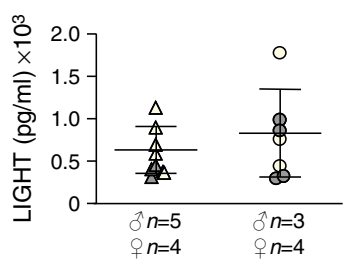

d

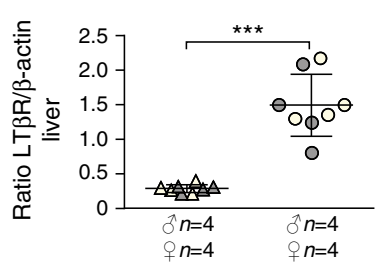

g

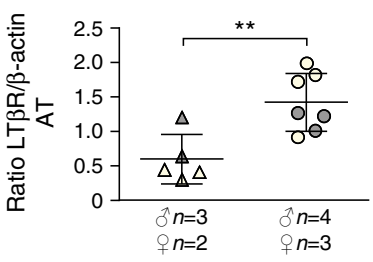

b

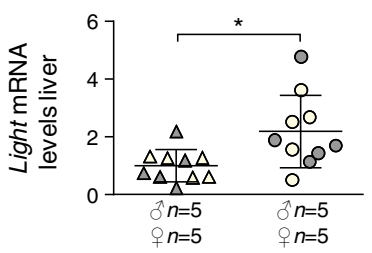

e

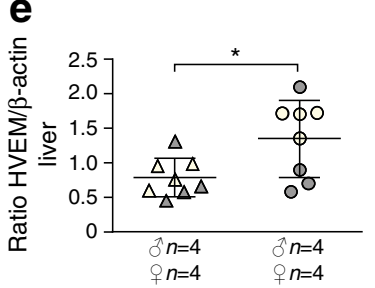

h

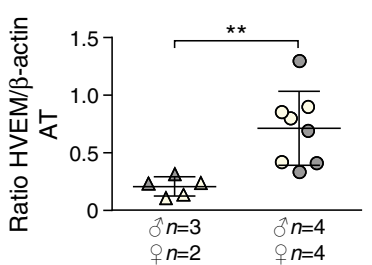

C

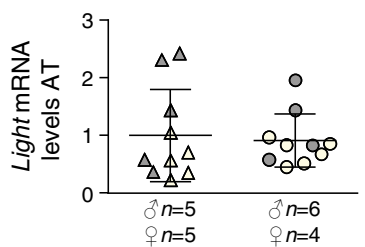

f

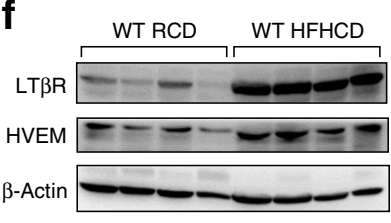

i

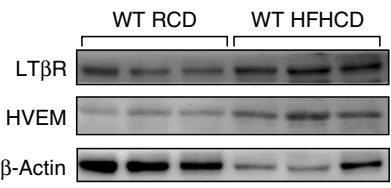

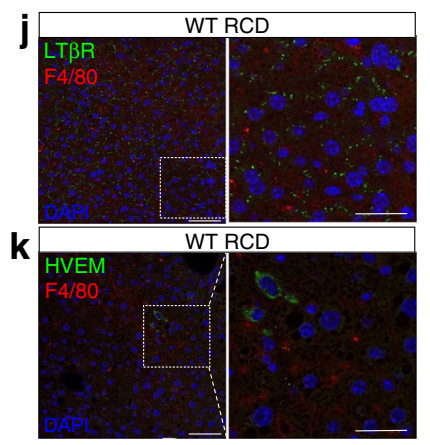
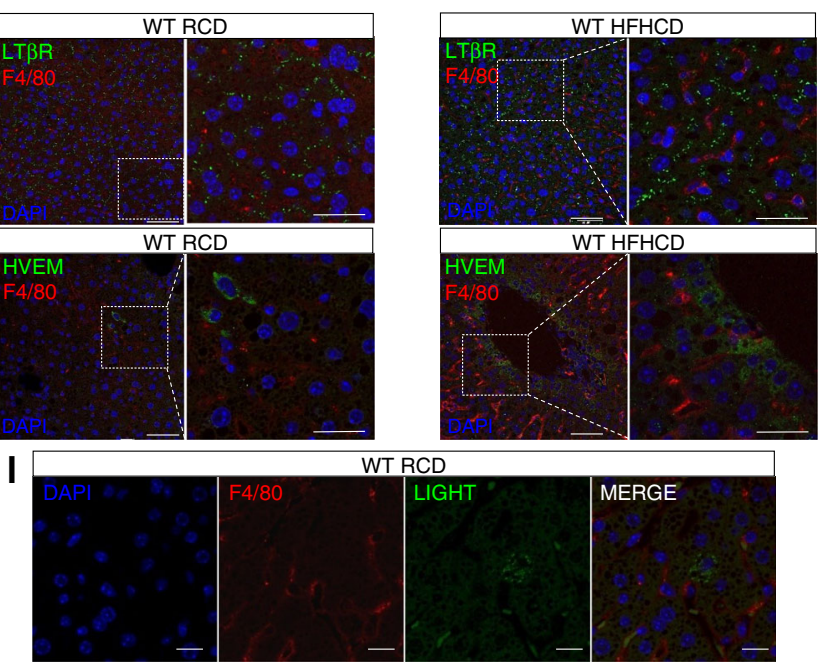

WT HFHCD

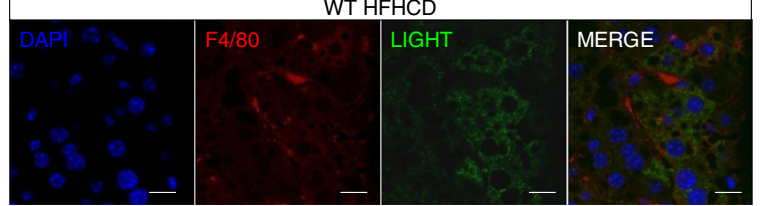

weight (ESM Fig. 1a-d). Similarly, fasting glucose and insulin levels (Fig. 2a, b) were indistinguishable between mouse groups. No changes were observed in the GTT measured as the $\mathrm{AUC}_{\text {glucose }}$ variable, or in glucose-stimulated insulin release, measured as $\mathrm{AUC}_{\text {insulin, }}$ or in the ITT (Fig. 2c-e). Similarly, Light deficiency did not change body weight, body fat mass content or distribution, liver weight (ESM Fig. 2a-d), fasting glucose or insulin levels (Fig. 2f, g) in mice placed on
HFHCD. However, GTT revealed improved glucose tolerance, measured as the $\mathrm{AUC}_{\text {glucose }}$ variable (Fig. $2 \mathrm{~h}$ ), in Light-deficient mice compared with controls. No differences were observed in the glucose-stimulated insulin release during the GTT, measured as the $\mathrm{AUC}_{\text {insulin }}$ at 120 min of the test (Fig. 2i). However, $\mathrm{AUC}_{\text {insulin }}$ at $30 \mathrm{~min}$ in $\mathrm{Light}^{-/}$mice displayed an increase in insulin release compared with WT mice (Fig. 2i). ITT demonstrated improved insulin sensitivity in $\mathrm{Light}^{-}$ 

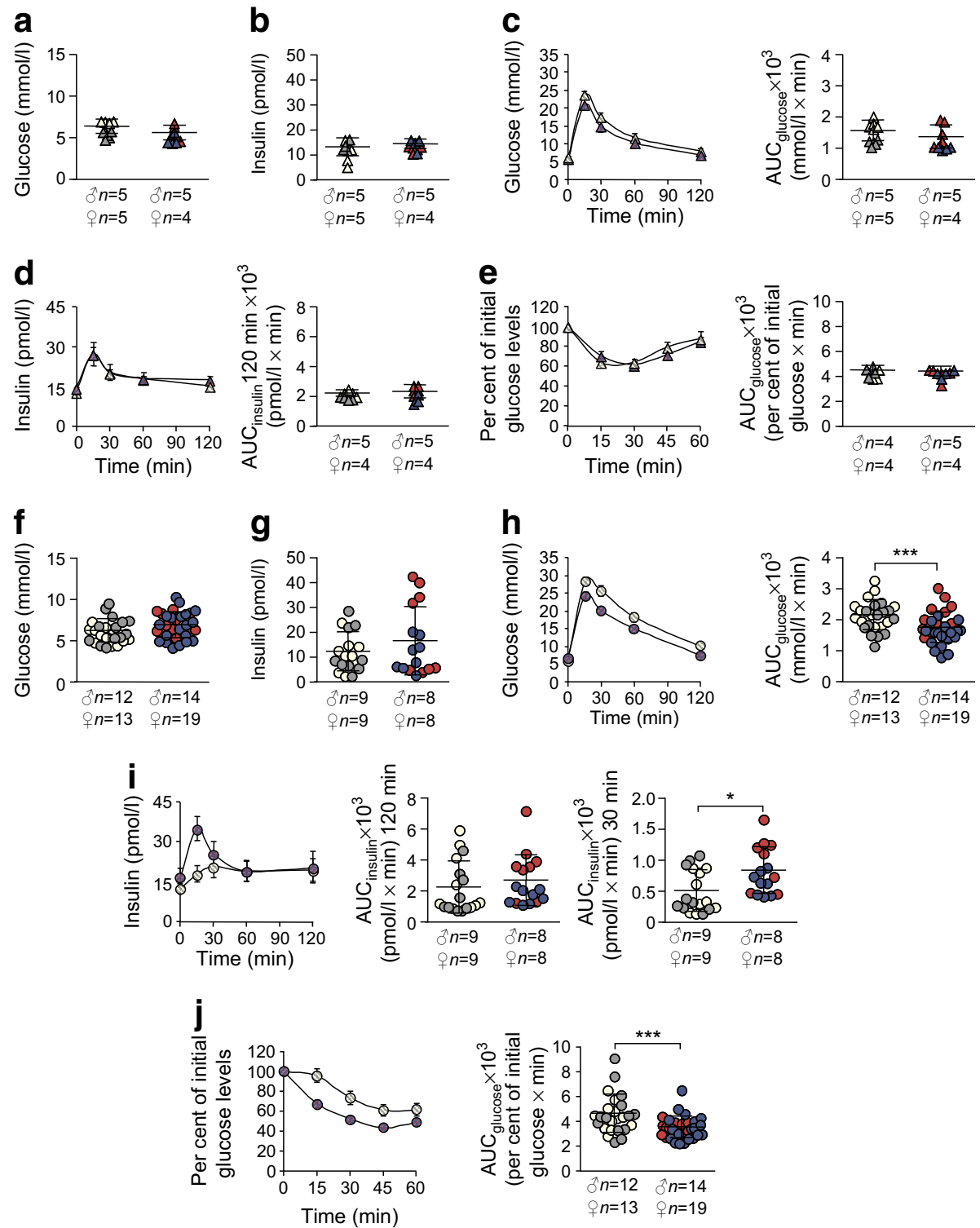

Fig. 2 Metabolic characterisation of WT and $\mathrm{Light}^{-{ }^{-}}$mice fed for 16 weeks with an RCD or an HFHCD. Plasma fasting (a) glucose and (b) insulin levels in WT and $\mathrm{Light}^{-/}$mice fed an RCD. Plasma (c) glucose and (d) insulin levels at the different time points during the GTT, which were used to calculate the $\mathrm{AUC}_{\text {glucose }}(\mathbf{c})$ and $\mathrm{AUC}_{\text {insulin }}$ (d), in RCD-fed WT and $\mathrm{Light}^{-/}$mice. (e) Plasma glucose levels (as a percentage relative to the initial glucose levels) during the ITT, together with the $\mathrm{AUC}_{\text {glucose }}$, in RCD-fed WT and $\mathrm{Light}^{-/-}$mice. Plasma fasting (f) glucose and (g) insulin levels in WT and $\mathrm{Light}^{-1-}$ mice fed HFHCD. Plasma fasting (h) glucose and (i) insulin levels at the different time points

mice, as revealed by a decrease in the $\mathrm{AUC}_{\text {glucose }}$ (Fig. $2 \mathrm{j}$ ). Analysis of lipids indicated no effect of Light deficiency in total cholesterol, ApoB-cholesterol, HDL-cholesterol and triacylglycerol either in mice fed an RCD (ESM Fig. 1e-h) or mice fed HFHCD (ESM Fig. 2e-h). Therefore, Light deficiency does not have an effect in mice fed an RCD, but improves glucose tolerance and insulin sensitivity in mice fed HFHCD without changes in lipid plasma levels. during the GTT and the $\mathrm{AUC}_{\text {glucose }}(\mathbf{h})$ and $\mathrm{AUC}_{\text {insulin }}$ at 120 and 30 min (i) in WT and $\mathrm{Light}^{-1-}$ mice fed HFHCD. (j) Plasma glucose levels (as a percentage relative to the initial glucose levels) during the ITT, together with $\mathrm{AUC}_{\text {glucose }}$, in mice fed HFHCD. Triangles, RCD-fed mice; circles, HFHCD-fed mice; white, male WT mice; grey, female WT mice; red, male $\mathrm{Light}^{-1-}$ mice; blue, female $\mathrm{Light}^{-{ }^{-}}$mice; hatched lines indicate both male and female mice. The line graphs in $(\mathbf{c}-\mathbf{e})$ and $(\mathbf{h}-\mathbf{j})$ show the mean of males and females. All other data are shown as individual data points with mean \pm SEM. Statistical analysis was performed using Student's $t$ test $\left(* p<0.05\right.$ and $\left.{ }^{* * *} p<0.001\right)$

Light deficiency in RCD-fed mice did not affect hepatic triacylglycerol content, steatosis, ballooning, lobular inflammation or NAS score (Fig. 3a, c, e, g, i). But, Light $^{-/-}$mice fed HFHCD showed significantly diminished hepatic triacylglycerol content (Fig. 3b), hepatic steatosis (Fig. 3d), lobular inflammation (Fig. 3h) and NAS score (Fig. 3j) without changes in ballooning score (Fig. 3f). No differences in hepatic F4/80 $0^{+}$ macrophage and $\mathrm{CD}^{+}$lymphocyte contents or collagen in 
Fig. 3 Hepatic characterisation in WT and $\mathrm{Light}^{-/}$mice fed for 16 weeks with an RCD and HFHCD. Analysis of (a, b) triacylglycerol content, $(\mathbf{c}, \mathbf{d})$ steatosis score, $(\mathbf{e}, \mathbf{f})$ hepatocyte ballooning, $(\mathbf{g}, \mathbf{h})$ lobular inflammation and (i, j) NAS score, in mice fed an RCD (a, c, e, $\mathbf{g}$, i) and $\operatorname{HFHCD}(\mathbf{b}, \mathbf{d}, \mathbf{f}, \mathbf{h}, \mathbf{j})$. (k) Representative images of steatosis, hepatocyte ballooning and lobular inflammation. Scale bars, $50 \mu \mathrm{m}$. Triangles, RCD-fed mice; circles, HFHCD-fed mice; white, male WT mice; grey, female WT mice; red, male Light $^{-1-}$ mice; blue, female Light $^{-/}$mice. Data are shown as individual data points with mean \pm SEM. Statistical analysis was performed using Student's $t$ test $(\mathbf{a}, \mathbf{b}, \mathbf{d}, \mathbf{i}, \mathbf{j})$ and Mann-Whitney $U$ test $(\mathbf{c}, \mathbf{e}-\mathbf{h})\left({ }^{*} p<0.05,{ }^{* *} p<\right.$ 0.01 and $* * * p<0.001)$
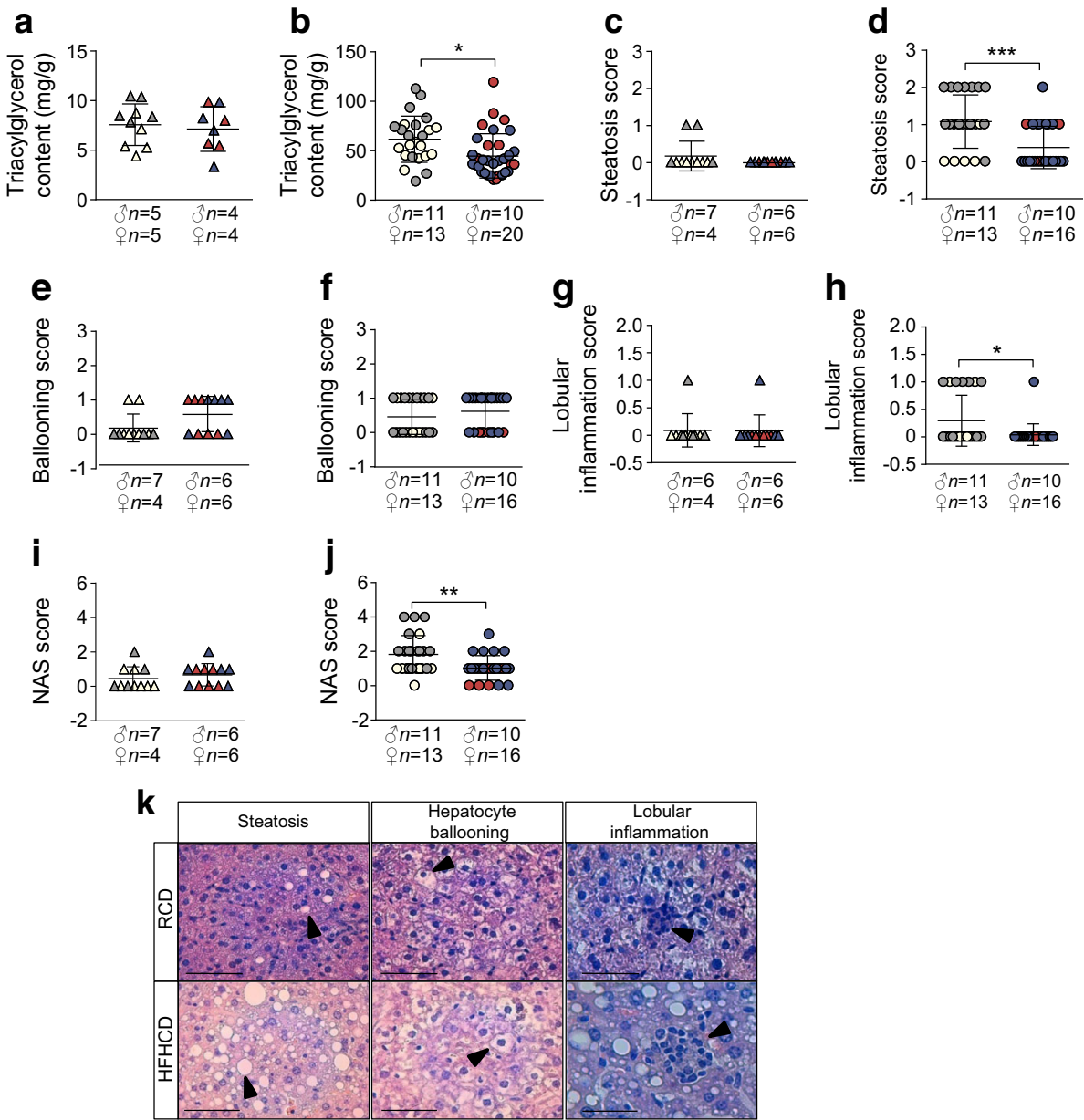

RCD-fed mice (Fig. 4a, d, g) were observed, but $\operatorname{Light}^{-/}$mice fed HFHCD displayed diminished macrophage and $\mathrm{CD}^{+}$ lymphocytes compared with controls (Fig. 4b, e) without changes in fibrosis (Fig. 4h). No changes were seen in the activity of ALT or AST between genotypes in any dietary regimen (Fig. 4j, k, l, m). Comparison between the two dietary regimens in WT mice showed enhanced triacylglycerol and F4 $/ 80^{+}$macrophage contents (ESM Fig. $3 \mathrm{a}, \mathrm{b}$ ) in mice fed HFHCD.

Analysis of hepatic gene expression showed augmented mRNA levels of Cd11c, Zbtb16 and Tbet (Fig. 5a, c, d), which are determinant for proinflammatory macrophages, natural killer T (NKT) cell identity and proinflammatory Th1, respectively, in HFHCD-fed WT mice compared with RCD-fed WT controls. Consistently, mRNA expression of Cd206, Gata3 and Foxp3 (Fig. 5b, e, g), markers of anti-inflammatory macrophages, Th2 subset and Treg cells, respectively, were significantly decreased in WT and Light ${ }^{-1-}$ HFHCD-fed mice compared with their respective RCD-fed mice. Comparison between ight $^{-1}$ and WT mice indicated decreased mRNA expression of Zbtb16 in mice fed HFHCD (Fig. 5c) and diminished anti-inflammatory $C d 206$ and Foxp 3 (Fig. 5b, g) in $\mathrm{Light}^{-/}$mice compared with controls fed an RCD. mRNA expression analysis of genes related to hepatic stellate cell activation, Colla1 and Acta2, or genes associated with fibrosis, such as cytokine $T g f b 1, M m p 9$ and Timp 1, did not display changes among mouse groups (Fig. 5h-1).

These data indicate that HFHCD induces inflammation which is alleviated by Light deficiency.

Deficiency of Light reduces adipose tissue and systemic inflammation in WT mice fed HFHCD NAFLD and hepatic inflammation might be induced by dysfunctional visceral adipose tissue [22]. Analysis of male mouse adipose tissue showed decreased cytokine secretion of monocyte chemoattractant protein 1 (MCP1), TNF- $\alpha$ and IL-17 by adipose tissue explants from Light $^{-/}$mice compared with those secreted by WT controls (Fig. 6a, b, d). No differences were observed in IL-6 secretion from adipose tissue between mouse groups (Fig. 6c). In agreement with reduced proinflammatory cytokine secretion in adipose tissue, analysis of SVFs revealed a reduced percentage of the proinflammatory $\mathrm{F} 4 / 80^{+} \mathrm{CD} 11 \mathrm{c}^{+} \mathrm{ATMs}$ in female mice (Fig. 6i) and augmented levels of the anti-inflammatory F4/ $80^{+} \mathrm{CD}^{2} 06^{+}$ATMs in $\mathrm{Light}^{--}$male mice (Fig. $6 \mathrm{~g}$ ) without changes in total $\mathrm{F} 4 / 80^{+}$ATMs (Fig. 6e, h). Analysis of the transcription factor determinants of immune cellular subset 
Fig. 4 Hepatic characterisation in WT and $\mathrm{Light}^{-/}$mice fed for 16 weeks with an RCD and an HFHCD. Hepatic cross-sectional analysis of $(\mathbf{a}-\mathbf{c})$ macrophage $\mathrm{F} 4$ $80^{+}$and (d-f) lymphocyte $\mathrm{CD}^{+}$ contents (cell number relative to hepatic area in $\mu \mathrm{m}^{2}$ ) in WT and $\operatorname{Light}^{-/}$mice fed an RCD (a, d) or $\operatorname{HFHCD}(\mathbf{b}, \mathbf{e})$. $(\mathbf{c}, \mathbf{f})$

Representative images of (c) F4/

80 immunohistochemistry and (f)

CD3 immunofluorescence for

both dietary regimens and

genotypes. (g-i) Percentage of collagen in Masson trichrome staining in WT and $\mathrm{Light}^{-/}$mice fed (g) an RCD or (h) an HFHCD Representative images of (i) collagen stainings are shown for both dietary regimens and genotypes. Plasma levels of $(\mathbf{j}, \mathbf{k})$ ALT and $(\mathbf{l}, \mathbf{m})$ AST activity in RCD-fed (j, l) and HFHCD-fed

$(\mathbf{k}, \mathbf{m})$ mice. Scale bars, $(\mathbf{c}, \mathbf{i})$

$50 \mu \mathrm{m}$ and (f) $20 \mu \mathrm{m}$. Triangles, RCD-fed mice; circles, HFHCDfed mice; white, male WT mice; grey, female WT mice; red, male Light $^{-1}$ mice; blue, female

Light $^{-/}$mice. Data are shown as individual data points with mean \pm SEM. Statistical analysis was performed using Student's $t$ test $(\mathbf{a}, \mathbf{b}, \mathbf{d}, \mathbf{g}, \mathbf{h}, \mathbf{j}-\mathbf{m})$ and MannWhitney $U$ test (c) $\left({ }^{\dagger} p=0.05\right.$ and $* p<0.05)$
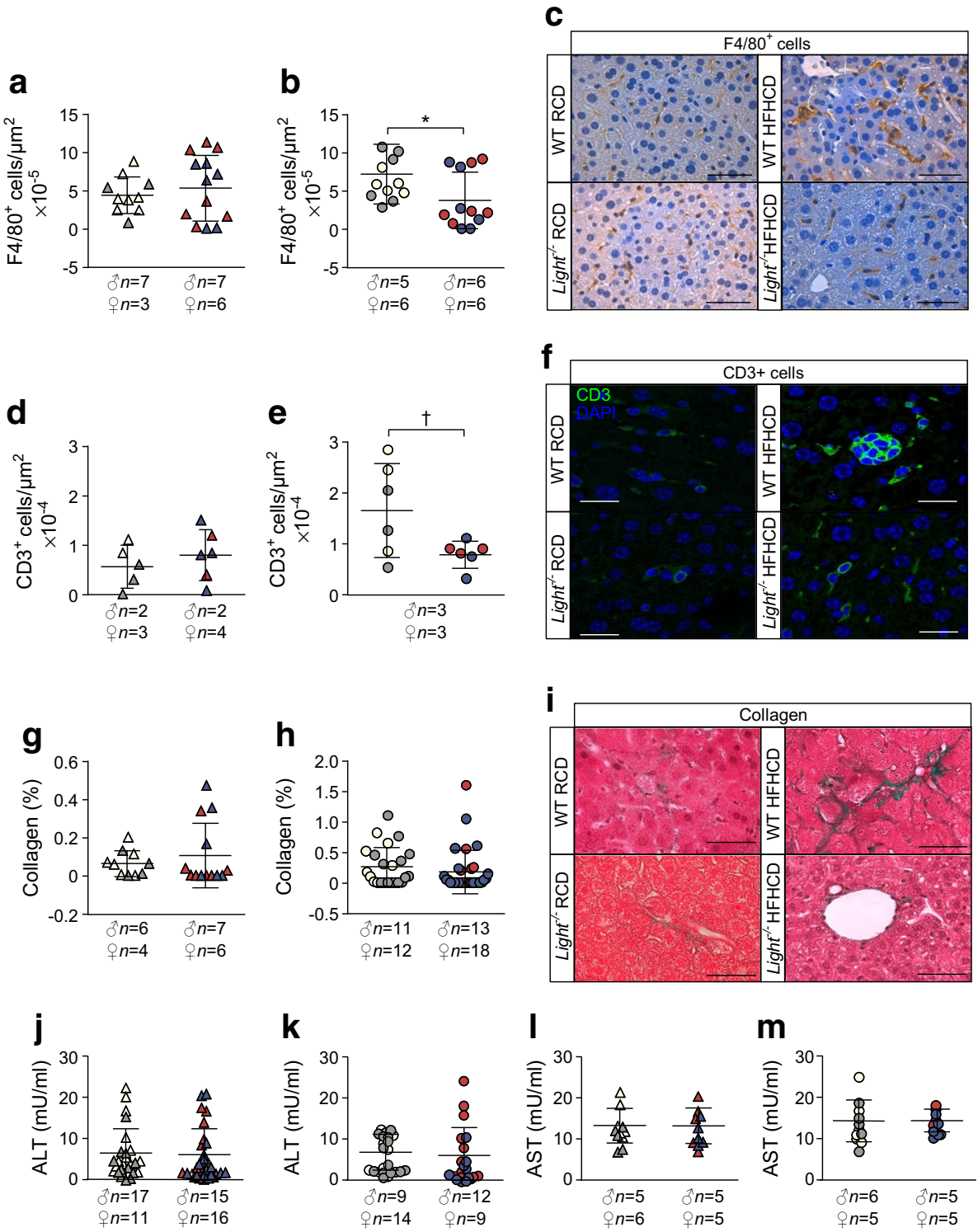

differentiation Tbet, Gata3, Rorc and Foxp3 did not reveal differences between $\mathrm{Light}^{-/}$and WT mice (Fig. 61-o).

Surprisingly, in contrast with these results, analysis of bone marrow-derived macrophages from $\mathrm{Light}^{-/}$female mice showed enhanced TNF- $\alpha$ and IL- 6 secretion and diminished IL-10 levels compared with WT female controls (ESM Fig. $4 \mathrm{~b}-\mathrm{d}$ ), thus indicating an intrinsic proinflammatory phenotype of Light-deficient macrophages. However, in vivo analysis showed diminished TNF- $\alpha$ and IL-6 circulating levels (Fig. $7 \mathrm{~b}, \mathrm{c})$. Likewise, in vivo Light deficiency reduced total $\mathrm{CD} 45^{+} \mathrm{CD} 115^{+}$monocytes in male mice (Fig. $7 \mathrm{~g}$ ), enhanced anti-inflammatory $\mathrm{CD} 45^{+} \mathrm{CD} 115^{+} \mathrm{Ly} 6 \mathrm{C}^{\text {low }}$ monocytes in both sexes (Fig. $7 \mathrm{~g}$, i) and decreased proinflammatory CD $45^{+} \mathrm{CD} 115^{+} \mathrm{Ly}_{6 \mathrm{C}}{ }^{\text {hi }}$ monocytes in female mice (Fig. $7 \mathrm{i}$ ). In addition, the $\mathrm{CD} 4^{+} \mathrm{CCR} 4^{-} \mathrm{CCR} 6^{+} \mathrm{Th} 9$ lymphocyte subset (Fig. 7n) was also reduced in HFHCD-fed $\mathrm{Light}^{-/-}$mice compared with WT controls. No major effect of Light deficiency was observed in circulating leucocytes (ESM Fig. 5ah) or in the adipose tissue macrophage phenotype of adipose tissue (ESM Fig. 5j-1) in RCD-fed mice. Of note, the CCR $4^{-} \mathrm{CCR} 6^{+} \mathrm{Th} 9$ population was increased in $\mathrm{Light}^{-/}$mice (ESM Fig. 5g). Hence, Light deficiency alleviates in vivo systemic and adipose tissue inflammation in HFHCD-fed mice.

Deficiency of Light reduces NAFLD, adipose tissue and systemic inflammation in Irs2 ${ }^{+/}$mice fed HFHCD Next, Light deficiency was evaluated in the hepatic physiopathology in $\mathrm{Irs} 2^{+/-}$mice, which display enhanced insulin resistance and NAFL during aging compared with age-matched WT [13]. Light deficiency diminished triacylglycerol (ESM Fig. 6a) and F4/80 $0^{+}$macrophage (ESM Fig. 6b) contents in Irs $2^{+/}$mice. As expected, compared with WT mice, Irs $2^{+/-}$mice displayed 

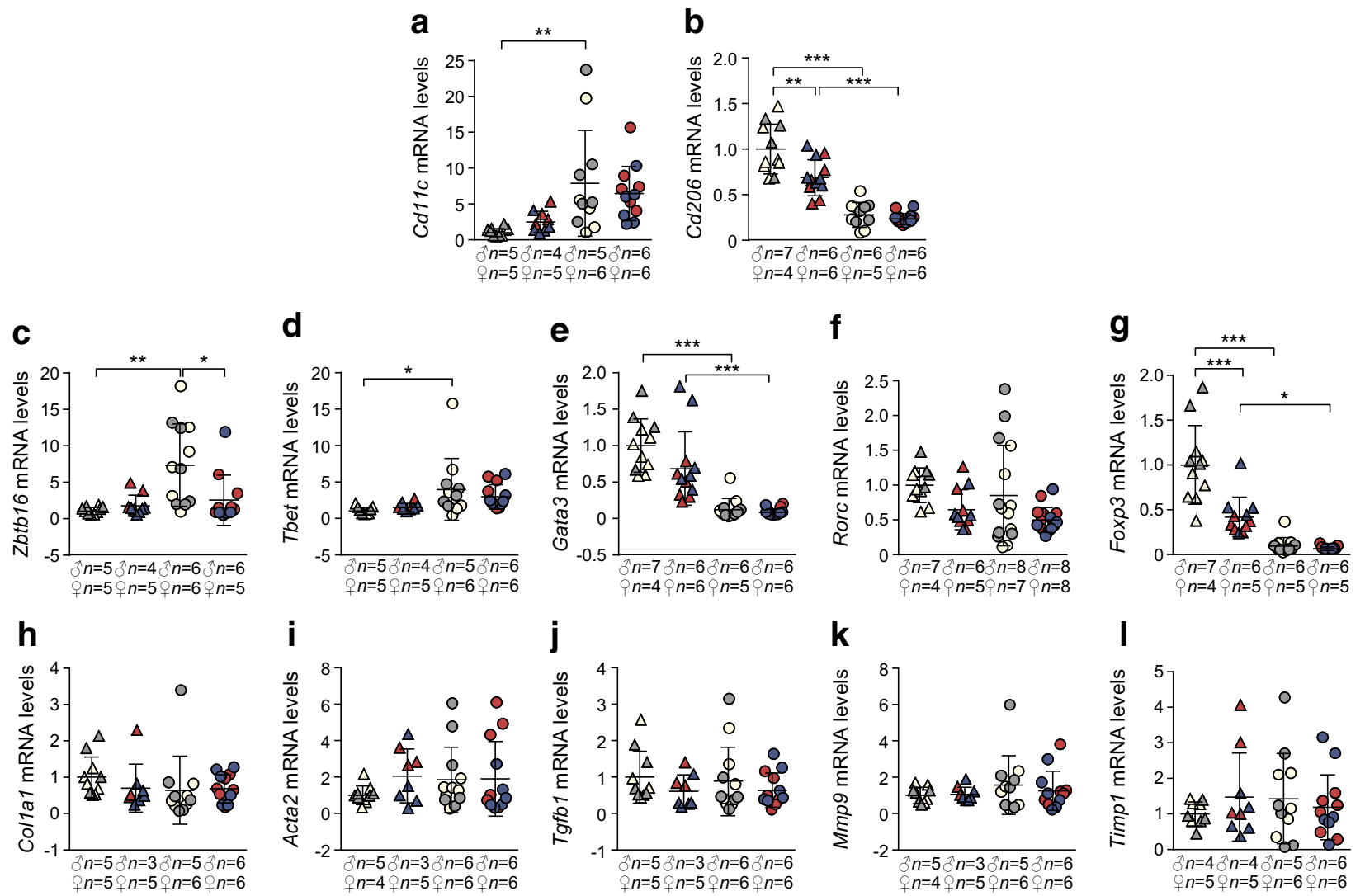

Fig. 5 Hepatic inflammatory and fibrosis marker analysis in WT and Light $^{-1}$ mice fed with an RCD and an HFHCD. mRNA levels of (a) $C d 11 c$ and (b) Cd206 macrophage surface markers, and (c) Zbtb16, (d) Tbet, (e) Gata3, (f) Rorc and (g) Foxp3 transcription factors in liver from all four groups of mice. mRNA levels of (h) Colla1, (i) Acta2, (j) Tgfbl, (k) Mmp9 and (I) Timpl in liver from all four groups of mice. mRNA levels were normalised to cyclophilin mRNA levels and are relative to

enhanced hepatic triacylglycerol and macrophage contents regardless of the presence of LIGHT (ESM Fig. 6d, e), indicating enhanced NAFLD in $I r s 2^{+/}$mice fed HFHCD. Circulating TNF- $\alpha$ and IL-17 cytokines (ESM Fig. 7b, d) were decreased in $\mathrm{IrS2}^{+/} \mathrm{Light}^{-/}$mice compared with $\mathrm{Irs} 2^{+/}$mice without differences in the other cytokines analysed (ESM Fig. 7a, c, e). Circulating leucocyte analysis showed no changes in lymphocytes, monocytes or neutrophils (ESM Fig. 7f) between mouse groups. Irs $2^{+-} \mathrm{Light}^{-/}$mice displayed augmented Ly6C low monocyte percentage and $\mathrm{CD} 4^{+} \mathrm{CCR} 4^{+} \mathrm{CCR} 6^{-} \mathrm{Th} 2$ cells (ESM Fig. $7 \mathrm{~g}, \mathrm{i}$ ), and diminished $\mathrm{CD} 4^{+} \mathrm{CXCR} 3^{+} \mathrm{Th} 1$, $\mathrm{CD} 4^{+} \mathrm{CCR} 4^{-} \mathrm{CCR} 6^{+} \mathrm{Th} 9$ and $\mathrm{CD} 4^{+} \mathrm{CCR} 4^{+} \mathrm{CCR} 6^{+}$Th17 subsets (ESM Fig. 7h, j, k). Irs2 $2^{+/}$Light $^{-/}$mouse adipose tissue also displayed diminished secretion of TNF- $\alpha$ and IL-17 cytokines (ESM Fig. $7 \mathrm{~m}, \mathrm{o}$ ) and diminished proinflammatory F4/ $80^{+} \mathrm{CD} 11 \mathrm{c}^{+}$ATMs and increased anti-inflammatory F4/ $80^{+} \mathrm{CD}^{206^{+}}$ATMs (ESM Fig. 7q, r). No changes in MCP1 and IL-6 secretion (ESM Fig. 71, n) or in total F4/80 $0^{+}$ATMs (ESM Fig. 7p) were observed. Thus, Light deficiency ameliorates NAFL and associated inflammation in $\mathrm{Irs} 2^{+/-}$mice fed HFHCD. levels in RCD-fed WT mouse. Triangles, RCD-fed mice; circles, HFHCD-fed mice; white, male WT mice; grey, female WT mice; red, male $\mathrm{Light}^{-/}$mice; blue, female $\mathrm{Light}^{-/}$mice. Data are shown as individual data points with mean \pm SEM. Statistical analysis was performed using two-way ANOVA followed by Tukey's post hoc multiple comparison test $(* p<0.05, * * p<0.01$ and $* * * p<0.001)$

Genetic inactivation of Light modulates hepatic expression in WT mice fed HFHCD LIGHT-dependent signalling might modulate metabolic gene expression in the liver [23]; thus, expression studies of hepatic metabolic genes related to lipogenesis, $\beta$-oxidation and gluconeogenesis were performed. Analysis showed decreased levels of Lxr, Pparg, Ppara and Abcal in Light ${ }^{-/}$mice (Fig. 8a, d, f, m), while Srebflc, Fasn and Ldlr mRNA levels were enhanced (Fig. 8b, e, l). Expression analysis of the Krüppel-like factor (KLF) family genes showed reduced mRNA levels of Klf6 in $\mathrm{Light}^{-/-}$mice compared with WT controls (Fig. 8s). Similarly, Light $^{-1-}$ mice displayed diminished Tlr4 levels (Fig. 8u). Thus, Light deficiency might reduce NAFLD by diminishing Klf6 and Tlr4, which associate with NASH.

\section{Discussion}

NAFLD is a major metabolic complication associated with type 2 diabetes mellitus and adipose tissue dysfunction. In the present study, we showed that genetic deficiency of 
Fig. 6 Adipose tissue characterisation in WT and Light ${ }^{-/}$mice fed with HFHCD. (a) MCP1, (b) TNF- $\alpha$, (c) IL-6 and (d) IL-17 cytokine secretion levels in adipose tissue from WT and Light $^{-1}$ mice. Analysis by flow cytometry of (e, h) total F4/ $80^{+}$, (f, i) proinflammatory F4/ $80^{+} \mathrm{CD} 11 \mathrm{c}^{+}$and $(\mathbf{g}, \mathbf{j})$ antiinflammatory $\mathrm{F} 4 / 80^{+} \mathrm{CD} 206^{+}$ macrophage content in live cells of SVFs from adipose tissue in males $(\mathbf{e}-\mathbf{g})$ and females $(\mathbf{h}-\mathbf{j})$. (k) Representative flow cytometry plots displaying the gating strategy for the different populations. mRNA levels of (I) Tbet, (m) Gata3, (n) Rorc and (o) Foxp3 transcription factors in adipose tissue from both groups of mice. mRNA levels were normalised to cyclophilin mRNA levels and are relative to levels in control WT mouse. Circles, HFHCD-fed mice; white, male WT mice; grey, female WT mice; red, male $\operatorname{Light}^{-/}$mice; blue, female $\mathrm{Light}^{-/}$mice. Data are shown as individual data points with mean \pm SEM. Statistical analysis was performed using Student's $t$ test $(* p<0.05$ and $* * * p<0.001)$. FSC, forward scatter
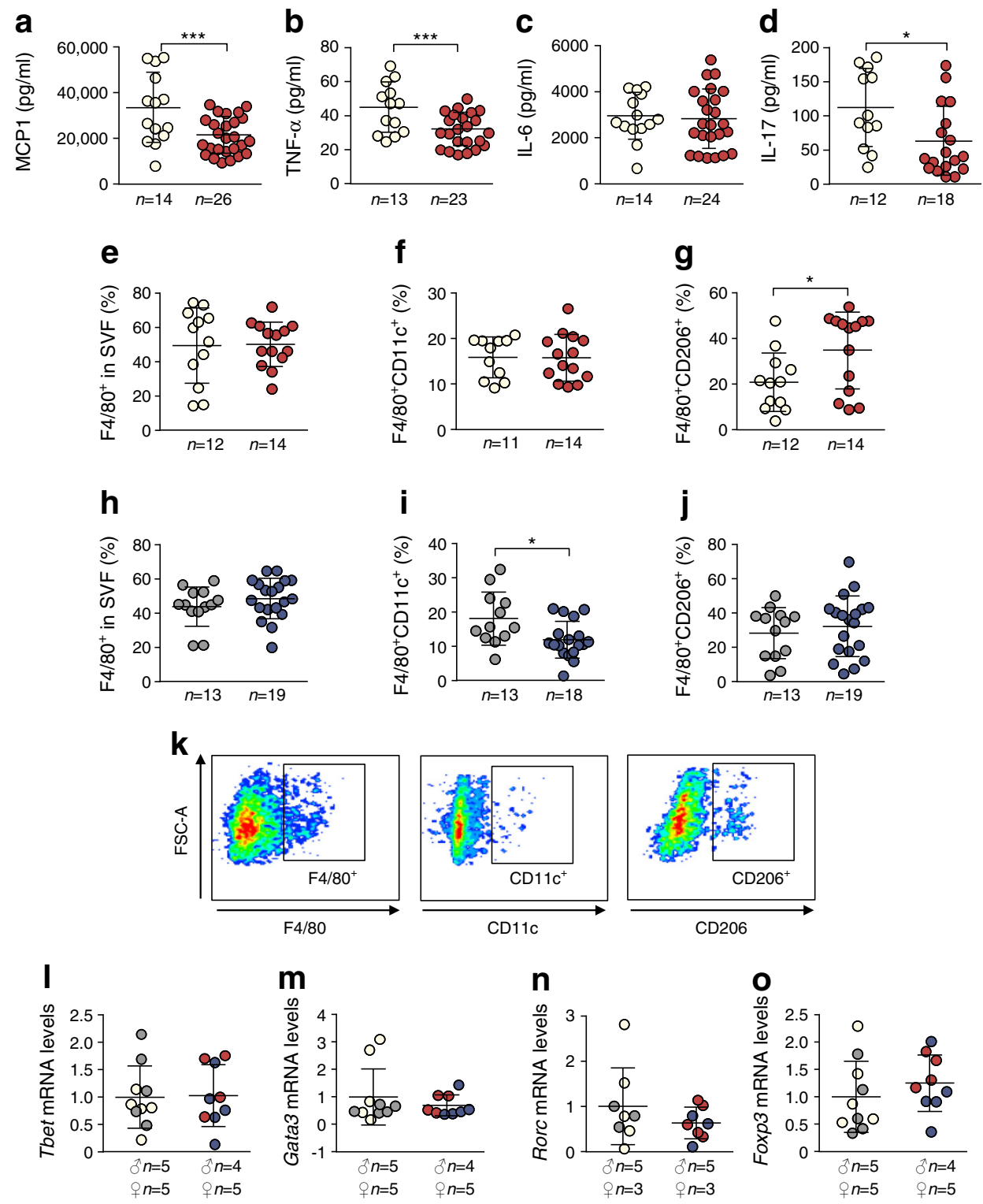

Light, a proinflammatory cytokine, did not affect metabolism, NAFL or inflammation in WT mice fed an RCD. However, Light ${ }^{-1}$ mice fed HFHCD displayed improved glucose tolerance, restored insulin sensitivity and decreased NAFL and hepatic inflammation compared with HFHCD-fed WT mice. Studies in RCD-fed and HFHCD-fed WT mice revealed augmented protein levels of LIGHT receptors, HVEM and LT $\beta$ R, and increased hepatic triacylglycerol, inflammatory markers and macrophage content, suggesting a role of LIGHTdependent signalling in NAFLD induced by HFHCD feeding. Moreover, adipose tissue from HFHCD-fed $\mathrm{Light}^{-1-}$ mice displayed decreased inflammation and diminished secretion of MCP1, TNF- $\alpha$ and IL-17 cytokines. In agreement with these findings, HFHCD-fed Light $^{-/}$mice displayed diminished circulating levels of $\mathrm{CD} 115^{+}$monocytes, $\mathrm{CCR} 4^{-} \mathrm{CCR} 6^{+}$ Th9 T cells, IL- 6 and TNF- $\alpha$ cytokines, while anti- inflammatory $\mathrm{CD} 115^{+} \mathrm{Ly} 6 \mathrm{C}^{\text {low }}$ monocytes were augmented. Hepatic analysis showed reduced content of $\mathrm{F} 4 / 80^{+}$macrophages, $\mathrm{CD}^{+} \mathrm{T}$ cells and mRNA levels of the transcription factor Zbtb16, determinant for NKT function, a cellular subset associated with liver complications. Similarly, Light deficiency in HFHCD-fed $I r s 2^{+/}$mice, which have impaired insulin signalling, also reduced NAFL and inflammation. Light $^{-/}$ mouse liver analysis also revealed a metabolic gene expression signature consistent with improved hepatic homeostasis and reduced mRNA levels of Klf6 and Tlr4, whose expression promotes NAFL-to-NASH and NASH-to-hepatocellular carcinoma (HCC) transitions. These results suggest that Light deficiency ameliorates deranged hepatic carbohydrate metabolism, NAFL and inflammation induced by HFHCD. Moreover, Light deficiency modulated immune cell phenotype, decreased inflammatory cytokine secretion and 
Fig. 7 Analysis of circulating cytokines and leucocyte subsets in WT and $\mathrm{Light}^{-/}$mice fed HFHCD. Circulating plasma levels of (a) MCP1, (b) TNF- $\alpha$, (c) IL-6, (d) IL-17 and (e) IFN- $\gamma$ in $\mathrm{Light}^{--}$and WT mice. (f, h) Percentages of circulating lymphocytes, monocytes and neutrophils identified in the CD $45^{+}$blood cell population by morphology and by the CD $115^{+}$ monocyte marker and $(\mathbf{g}, \mathbf{i})$ $\mathrm{CD} 45^{+} \mathrm{CD} 115^{+} \mathrm{Ly}_{6 \mathrm{C}^{\text {low }}}$ and $\mathrm{CD} 45^{+} \mathrm{CD} 115^{+}$Ly6 $\mathrm{C}^{\text {hi }}$ monocyte subset percentages identified in the $\mathrm{CD} 45^{+} \mathrm{CD} 115^{+}$cells in male $(\mathbf{f}, \mathbf{g})$ and female $(\mathbf{h}, \mathbf{i})$ mice. $(\mathbf{j}, \mathbf{k})$ Representative flow cytometry plots of the gating strategy for (j) leucocytes and (k) monocyte subsets in blood samples. Circulating levels of (I)

$\mathrm{CD}^{+}{ }^{+} \mathrm{CXCR}^{+} \mathrm{Th} 1,(\mathbf{m})$

$\mathrm{CD} 4^{+} \mathrm{CCR} 4^{+} \mathrm{CCR} 6^{-} \mathrm{Th} 2,(\mathbf{n})$ $\mathrm{CD} 4^{+} \mathrm{CCR} 4^{-} \mathrm{CCR}^{+}{ }^{+} \mathrm{Th} 9$ and (o) $\mathrm{CD}^{+} \mathrm{CCR}^{+} \mathrm{CCR}^{+}{ }^{+} \mathrm{Th} 17$ cellular subpopulations in WT and Light $^{-}$mice. (p)

Representative flow cytometry plots of the gating strategy for Th subpopulations in blood samples. Circles, HFHCD-fed mice; white, male WT mice; grey, female WT mice; red, male $\mathrm{Light}^{-/}$mice; blue, female $\mathrm{Light}^{-/}$mice. Data are shown as individual data points and with the mean \pm SEM. Statistical analysis was performed using Student's $t$ test (a, d-i, l-o) and Mann-Whitney $U$ test $(\mathbf{b}, \mathbf{c})$ $\left({ }^{*} p<0.05,{ }^{* *} p<0.01\right.$ and $* * * p<0.001)$. SSC, side scatter
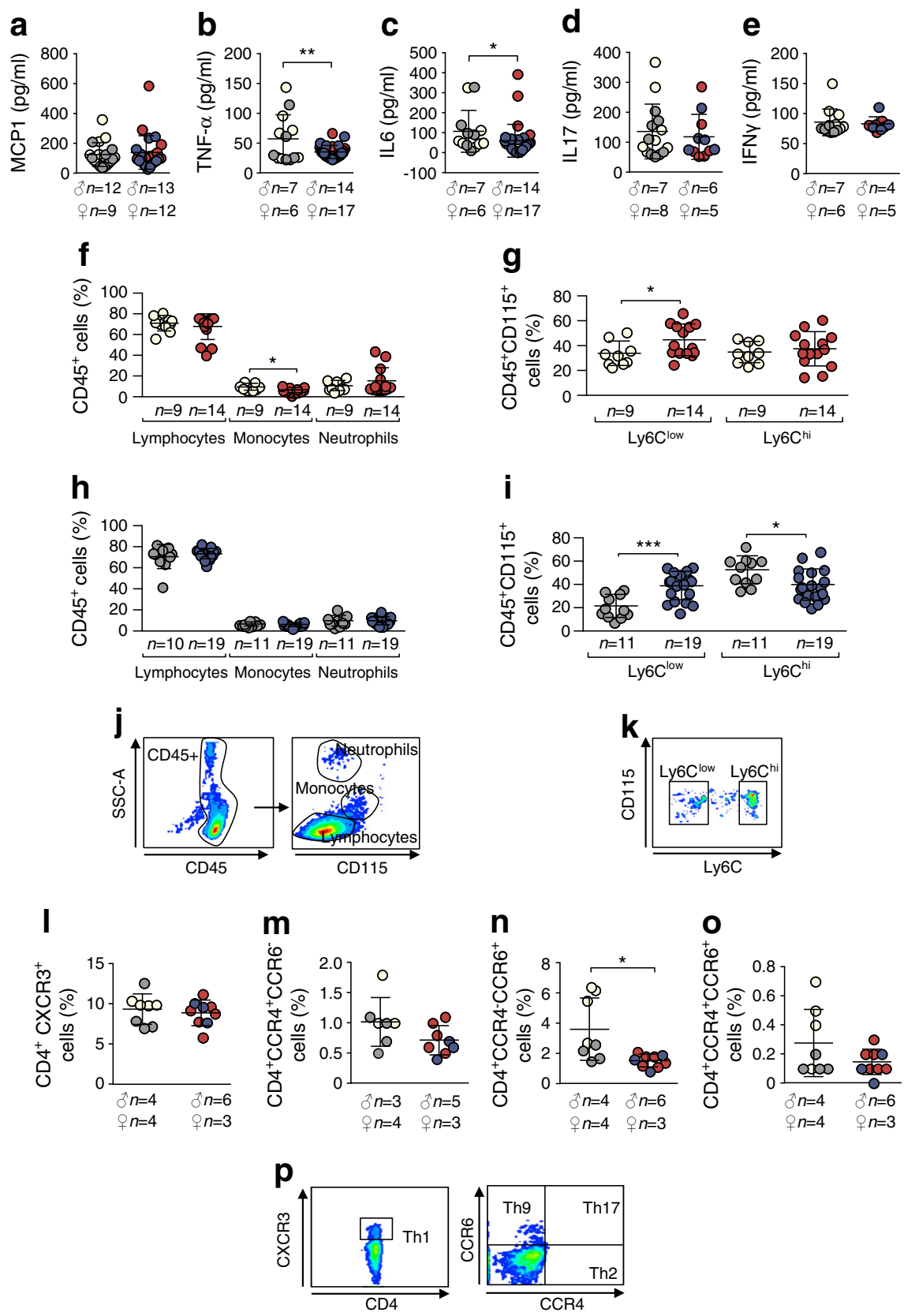

diminished pathways associated with NAFL-to-NASH transition, such as KLR6 and toll-like receptor 4 (TLR4). Altogether, these findings point to LIGHT-dependent signalling as a therapeutic target to restore hepatic homeostasis and to alleviate inflammation associated with NAFLD.

Earlier studies have shown elevated circulating LIGHT levels in individuals with insulin resistance/the metabolic syndrome [11] and type 2 diabetes mellitus [12]. We observed improved glucose tolerance in Light $^{-/}$mice fed HFHCD. Moreover, Light deficiency decreased insulin resistance in HFHCD-fed WT mice, suggesting that LIGHT could interfere with insulin sensitivity, as has been shown for other cytokines such as TNF- $\alpha$ [24]. LIGHT exerts important effects on circulating lipid levels by modulating hepatocyte gene expression and hepatic T lymphocytes [23, 25]. However Light deficiency did not modify circulating lipid levels in WT mice.

Notably, in agreement with previous investigations showing enhanced LIGHT levels in human NAFLD [10], Light deficiency reduced NAFLD, macrophage and T cell content in HFHCD-fed WT mice. Reduced hepatic inflammation in Light ${ }^{-1-}$ mice was accompanied by decreased inflammatory $\mathrm{CD} 11 \mathrm{c}^{+}$macrophages in adipose tissue, which is consistent with reports showing that adipose tissue inflammation signals the progression of NAFLD [22]. Moreover, adipose tissue transplantation from obese mice with a high $\mathrm{CD} 11 \mathrm{c}^{+}$cell content induced hepatic macrophage accumulation and liver 
Fig. 8 Hepatic expression in HFHCD-fed WT and Light $^{-1}$ mice. mRNA levels of (a) $L x r$, (b) Srebflc, (c) Chrebp, (d) Pparg, (e) Fasn, (f) Ppara, (g) Acox, (h) Pgcla, (i) Pepck, (j) G6pase, (k) Cd36, (l) Ldlr, (m) Abcal, (n) Abcg5, (o) Abcg8, (p) Cyp7al, (q) $K l f 2$, (r) Klf4, (s) Klf6, (t) Klf10 and (u) Tlr4 in Light $^{--}$and WT control mice. mRNA levels were normalised to endogenous cyclophilin expression and are relative to WT mouse levels. Circles, HFHCD-fed mice; white, male WT mice; grey, female WT mice; red, male $\mathrm{Light}^{-/}$mice; blue, female $\mathrm{Light}^{-/}$mice. Data are shown as individual data points with mean \pm SEM.

Statistical analysis was performed using Student's $t$ test $(\mathbf{a}-\mathbf{c}, \mathbf{e}-\mathbf{i}, \mathbf{k}-$ u) and Mann-Whitney $U$ test (d, j) $\left(^{\dagger} p=0.05, * p<0.05\right.$ and $* * * p<0.001)$
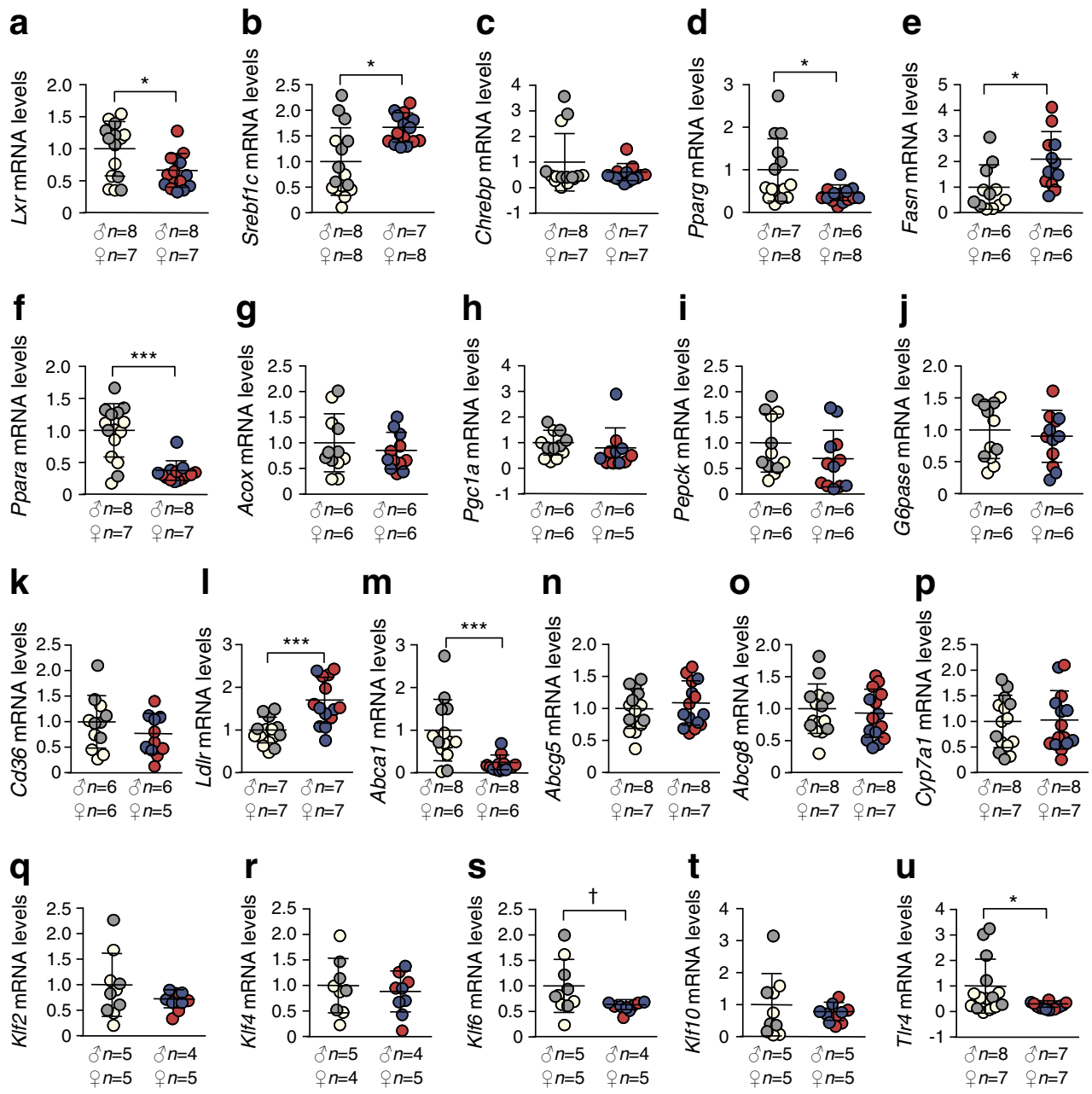

damage in high-cholesterol diet-fed $\mathrm{Ldlr}^{-/}$mice [26], which did not develop in RCD-fed mice. These findings suggest that adipose tissue with increased inflammatory $\mathrm{CD} 11 \mathrm{c}^{+}$cells, in the presence of HFHCD, might induce hepatic inflammation and that Light deficiency could alleviate inflammation by modulating adipose tissue dysfunction. In support of this hypothesis, LIGHT promotes adipose tissue dysfunction by inhibiting adipogenesis [27], which accommodates excess of fat, and exacerbates adipocyte inflammatory response [28]. In agreement with all of the above, adipose tissue explants from HFHCD-fed Light-deficient mice displayed decreased secretion of MCP1, TNF- $\alpha$ and IL-17, whose actions have been related to progression of insulin resistance, liver damage, fibrosis and NASH [29].

The above results indicate that LIGHT (TNFSF14) might alter hepatic homeostasis and function by reducing accumulation of inflammatory cells and inflammatory cytokine secretion. Nevertheless, Light deficiency also affected systemic inflammation. HFHCD-fed $\mathrm{Light}^{-1-}$ mice showed enhanced circulating Ly $6 \mathrm{C}^{\text {low }}$ monocytes and diminished circulating proinflammatory Th9 cells and TNF- $\alpha$ and IL- 6 cytokine levels. These data might indicate that Light deficiency reduces inflammatory potential of immune cells. However, unexpectedly, augmented secretion of proinflammatory IL-6 and TNF- $\alpha$ cytokines was observed in isolated bone marrowderived macrophages from $\mathrm{Light}^{-/-}$mice compared with WT controls, suggesting an anti-inflammatory role of LIGHT. In addition, immune cells in RCD-fed mice did not display major differences between $\mathrm{Light}^{-/}$and WT mice, with the exception of Th9 which was downregulated in HFHCD conditions but enhanced in RCD-fed $\mathrm{Light}^{-/}$mice. Altogether, this indicates that the immune cell phenotype in our experimental setting with HFHCD feeding is diet dependent and not developmental. On the other hand, in vivo macrophage Light deficiency by means of bone marrow transplantation studies showed a protective role of LIGHT (TNFSF14) in a diet-induced obesity model [30]. But, a previous report using a long-term inflammatory choline-deficient high-fat diet demonstrated augmented secretion of LIGHT by hepatic NKT cells during NASH-to-HCC transition, and consequently Light deficiency ameliorated disease progression [4]. Consistent with this, Light deficiency in HFHCD-fed mice reduced macrophage and $\mathrm{T}$ cell hepatic content, hepatic NKT transcription factor expression and NAFLD progression, 
suggesting a proinflammatory role of the cytokine by modulating different immune cells. Notably, the finding that LT $\beta R$ and HVEM expression was markedly augmented, in steatotic and inflamed liver upon HFHCD feeding, indicates that LIGHT-dependent signalling is relevant and induced by stress signals such as the HFHCD feeding. Altogether, this supports the hypothesis that the HFHCD phenotype is partly due to the LIGHT/LT $\beta$ R-HVEM axis and that defective signalling through this axis restrains NAFLD progression.

Altogether, our findings suggest that LIGHT has a complex role in hepatic metabolic diseases, having divergent effects depending on the experimental setting, diets and the mouse models used. Of note, our study showing that Light deficiency confers protection against NAFLD might be highly relevant in clinical scenarios such as a high dietary cholesterol content or in the presence of insulin resistance. Thus, Light deficiency in the absence of obesity and in cholesterol-enriched diets might potentially be protective since clinical data in NAFLD in lean individuals provide experimental evidence associating the presence of cholesterol in the diet with progression to NASH [31,32]. Likewise, Light deficiency might also be protective in insulin resistance, since the metabolic syndrome/insulin resistance individuals without obesity, who also display impaired insulin signalling [33], exhibit enhanced circulating LIGHT levels [11]. In this sense, Light deficiency decreased hepatic inflammation and steatosis, adipose tissue and systemic inflammation in HFHCD-fed $\operatorname{Irs} 2^{+/-}$mice, which display impaired insulin signalling and higher hepatic dysfunction than HFHCD-fed WT mice. Thus, therapies targeted to inhibit LIGHT might be of use in these clinical cases.

LT $\beta$ R-dependent signalling controls lipid homeostasis by modulating gene expression in the liver [23]. Analysis of lipogenic, $\beta$-oxidation and gluconeogenic genes did not consistently show improvement of these pathways in Light-deficient mice. Thus, protective Pparg and Ppara gene mRNA expression levels were unexpectedly decreased while mRNA levels of Srebflc, Ldlr and Fasn related to lipogenesis and lipid uptake were higher, which could alternatively indicate a compensatory mechanism induced by reduced hepatic lipid pool. In fact, Light-deficient mice had diminished $L x r$ and Abcal, whose activities are associated with aberrant lipid storage and accumulation of hepatic cholesterol pool in NAFLD $[34,35]$. Nevertheless, additional studies are required to fully understand the metabolic regulation of hepatic LIGHTmediated signalling. Consistent with improved NAFL, Light deficiency decreased important hepatic genes associated with liver damage such as Zbtb16 [4, 36], a transcription factor determinant for NKT cells, as well as Klf6 and Tlr4, whose function is highly relevant in the NAFL-to-NASH transition, hepatic stellate cell activation and HCC [36, 37]. Altogether, these findings indicate that Light deficiency might reduce NAFL progression by modulating relevant hepatic genes involved in NAFLD.
In summary, the present study showed that Light deficiency in HFHCD mice improves glucose tolerance and insulin sensitivity, and reduces NAFL, hepatic inflammation and adipose tissue proinflammatory cytokine secretion. In addition, Light deficiency produced a hepatic expression signature consistent with improved hepatic homeostasis and conferred protection against inflammation associated with NAFL-to-NASH transition by diminishing the hepatic expression of relevant actors in this pathologic process, Klf6 and Tlr4 genes. These results suggest that blocking LIGHT-dependent signalling might be of use in NAFLD in insulin resistance states and in NAFLD caused by cholesterol-enriched diets.

Acknowledgements We thank K. Pfeffer for providing Light-deficient mice, G. Herrera (Central Unit for Research in Medicine, INCLIVA, Spain) for assistance with flow cytometry analysis and A. Díaz (Central Unit for Research in Medicine, University of Valencia, Spain) for help with animal care.

Data availability All data generated or analysed during this study are included in the published article (and its additional files). Data regarding the manuscript are available upon reasonable request made to the corresponding author.

Funding This study was supported by grants from the Carlos III Health Institute (PI16/00091 awarded to HG-N), Generalitat Valenciana (APOTIP/2018/02 to HG-N), the European Regional Development Fund (FEDER) and a grant from the European Foundation for the Study of Diabetes/Novo Nordisk (Programme for Diabetes Research in Europe) awarded to HG-N. HG-N is an investigator in the Miguel Servet II programme (CP16/00013). AV and AH-C received salary support from the European Foundation for the Study of Diabetes/NOVO Nordisk and from Proyecto Paula (a Fundraising initiative for the study of Diabetes). This work was also supported by CIBERDEM (CB07/08/0043 to DJB), a Carlos III Health Institute initiative. The study sponsors were not involved in the design of the study; the collection, analysis, and interpretation of data; writing the report; or the decision to submit the report for publication.

Duality of interest The authors declare that there is no duality of interest associated with this manuscript.

Contribution statement $\mathrm{AH}-\mathrm{C}$ and $\mathrm{AV}$ acquired and analysed all of the data, participated in the interpretation of results and helped to write the manuscript. DJB participated in study design, writing and critical revision of the manuscript. HG-N conceived and designed the study, supervised the data acquisition, interpreted the results and wrote the manuscript. All authors gave final approval of the version to be published. HG-N is the guarantor of this work.

\section{References}

1. World Health Organization (2016) Global report on diabetes. https://apps.who.int/iris/bitstream/handle/10665/204871/ 9789241565257 eng.pdf? sequence $=1$

2. Anstee QM, Targher G, Day CP (2013) Progression of NAFLD to diabetes mellitus, cardiovascular disease or cirrhosis. Nat Rev Gastroenterol Hepatol 10(6):330-344. https://doi.org/10.1038/ nrgastro.2013.41 
3. Cohen JC, Horton JD, Hobbs HH (2011) Human fatty liver disease: old questions and new insights. Science 332(6037):1519-1523. https://doi.org/10.1126/science.1204265

4. Wolf MJ, Adili A, Piotrowitz K et al (2014) Metabolic activation of intrahepatic CD8+ T cells and NKT cells causes nonalcoholic steatohepatitis and liver cancer via cross-talk with hepatocytes. Cancer Cell 26(4):549-564. https://doi.org/10.1016/j.ccell.2014. 09.003

5. Buzzetti E, Pinzani M, Tsochatzis EA (2016) The multiple-hit pathogenesis of non-alcoholic fatty liver disease (NAFLD). Metabolism 65(8):1038-1048. https://doi.org/10.1016/j.metabol.2015.12.012

6. Wouters K, van Gorp PJ, Bieghs V et al (2008) Dietary cholesterol, rather than liver steatosis, leads to hepatic inflammation in hyperlipidemic mouse models of nonalcoholic steatohepatitis. Hepatology 48(2):474-486. https://doi.org/10.1002/hep.22363

7. Doherty TA, Soroosh P, Khorram N et al (2011) The tumor necrosis factor family member LIGHT is a target for asthmatic airway remodeling. Nat Med 17(5):596-603. https://doi.org/10.1038/nm. 2356

8. Lin WW, Hsieh SL (2011) Decoy receptor 3: a pleiotropic immunomodulator and biomarker for inflammatory diseases, autoimmune diseases and cancer. Biochem Pharmacol 81(7):838-847. https://doi.org/10.1016/j.bcp.2011.01.011

9. Shaikh RB, Santee S, Granger SW et al (2001) Constitutive expression of LIGHT on T cells leads to lymphocyte activation, inflammation, and tissue destruction. J Immunol 167(11):6330-6337. https://doi.org/10.4049/jimmunol.167.11.6330

10. Otterdal K, Haukeland JW, Yndestad A et al (2015) Increased serum levels of LIGHT/TNFSF14 in nonalcoholic fatty liver disease: possible role in hepatic inflammation. Clin Transl Gastroenterol 6(7):e95. https://doi.org/10.1038/ctg.2015.23

11. Andres-Blasco I, Vinue A, Herrero-Cervera A et al (2016) Hepatic lipase inactivation decreases atherosclerosis in insulin resistance by reducing LIGHT/lymphotoxin $\beta$-receptor pathway. Thromb Haemost 116(2):379-393. https://doi.org/10.1160/TH15-10-0773

12. Halvorsen B, Santilli F, Scholz H et al (2016) LIGHT/TNFSF14 is increased in patients with type 2 diabetes mellitus and promotes islet cell dysfunction and endothelial cell inflammation in vitro. Diabetologia 59(10):2134-2144. https://doi.org/10.1007/s00125016-4036-y

13. Vinue A, Andres-Blasco I, Herrero-Cervera A et al (2015) Ink4/Arf locus restores glucose tolerance and insulin sensitivity by reducing hepatic steatosis and inflammation in mice with impaired IRS2dependent signalling. Biochim Biophys Acta 1852(9):1729-1742. https://doi.org/10.1016/j.bbadis.2015.05.013

14. González-Navarro H, Nong Z, Amar MJ et al (2004) The ligandbinding function of hepatic lipase modulates the development of atherosclerosis in transgenic mice. J Biol Chem 279(44):4531245321. https://doi.org/10.1074/jbc.M406495200

15. Vinue A, Navarro J, Herrero-Cervera A et al (2017) The GLP-1 analogue lixisenatide decreases atherosclerosis in insulin-resistant mice by modulating macrophage phenotype. Diabetologia 60(9): 1801-1812. https://doi.org/10.1007/s00125-017-4330-3

16. Andres-Blasco I, Herrero-Cervera A, Vinue A et al (2015) Hepatic lipase deficiency produces glucose intolerance, inflammation and hepatic steatosis. J Endocrinol 227(3):179-191. https://doi.org/10. 1530/JOE-15-0219

17. Norris AW, Chen L, Fisher SJ et al (2003) Muscle-specific PPAR $\gamma$ deficient mice develop increased adiposity and insulin resistance but respond to thiazolidinediones. J Clin Invest 112(4):608-618. https://doi.org/10.1172/JCI17305

18. Gonzalez-Navarro H, Vinue A, Sanz MJ et al (2013) Increased dosage of Ink4/Arf protects against glucose intolerance and insulin resistance associated with aging. Aging Cell 12(1):102-111. https:// doi.org/10.1111/acel.12023
19. Asgharpour A, Cazanave SC, Pacana T et al (2016) A diet-induced animal model of non-alcoholic fatty liver disease and hepatocellular cancer. J Hepatol 65(3):579-588. https://doi.org/10.1016/j.jhep. 2016.05.005

20. Mahnke YD, Beddall MH, Roederer M (2013) OMIP-017: human CD4(+) helper T-cell subsets including follicular helper cells. Cytometry A 83(5):439-440

21. Vinue A, MartInez-HervAs S, Herrero-Cervera A et al (2018) Changes in CDKN2A/2B expression associate with $\mathrm{T}$ cell phenotype modulation in atherosclerosis and type 2 diabetes mellitus. Transl Res 203:31-48

22. Duval C, Thissen U, Keshtkar S et al (2010) Adipose tissue dysfunction signals progression of hepatic steatosis towards nonalcoholic steatohepatitis in C57BL/6 mice. Diabetes 59(12):3181-3191. https://doi.org/10.2337/db10-0224

23. Lo JC, Wang Y, Tumanov AV et al (2007) Lymphotoxin $\beta$ receptordependent control of lipid homeostasis. Science 316(5822):285288. https://doi.org/10.1126/science. 1137221

24. Lee BC, Lee J (2014) Cellular and molecular players in adipose tissue inflammation in the development of obesity-induced insulin resistance. Biochim Biophys Acta 1842(3):446-462. https://doi. org/10.1016/j.bbadis.2013.05.017

25. Chellan B, Koroleva EP, Sontag TJ et al (2013) LIGHT/TNFSR14 can regulate hepatic lipase expression by hepatocytes independent of T cells and Kupffer cells. PLoS One 8(1):e54719. https://doi.org/ 10.1371/journal.pone.0054719

26. Bijnen M, Josefs T, Cuijpers I et al (2018) Adipose tissue macrophages induce hepatic neutrophil recruitment and macrophage accumulation in mice. Gut 67(7):1317-1327. https://doi.org/10.1136/ gutjnl-2016-313654

27. Tiller G, Laumen H, Fischer-Posovszky P et al (2011) LIGHT (TNFSF14) inhibits adipose differentiation without affecting adipocyte metabolism. Int J Obes 35(2):208-216. https://doi.org/10. 1038/ijo.2010.126

28. Kim HM, Jeong CS, Choi HS, Kawada T, Yu R (2011) LIGHT/ TNFSF14 enhances adipose tissue inflammatory responses through its interaction with HVEM. FEBS Lett 585(3):579-584. https://doi. org/10.1016/j.febslet.2011.01.011

29. Wree A, Inzaugarat ME, Feldstein AE (2018) Transmembrane BAX inhibitor motif-containing 1, a novel anti-inflammatory approach for nonalcoholic steatohepatitis treatment. Hepatology 67(1):438-441. https://doi.org/10.1002/hep.29495

30. Saunders BM, Rudnicka C, Filipovska A et al (2018) Shining LIGHT on the metabolic role of the cytokine TNFSF14 and the implications on hepatic IL-6 production. Immunol Cell Biol 96(1):41-53. https://doi.org/10.1111/imcb.1002

31. Ioannou GN, Morrow OB, Connole ML, Lee SP (2009) Association between dietary nutrient composition and the incidence of cirrhosis or liver cancer in the United States population. Hepatology 50(1):175-184. https://doi.org/10.1002/hep.22941

32. Yasutake K, Nakamuta M, Shima Y et al (2009) Nutritional investigation of non-obese patients with non-alcoholic fatty liver disease: the significance of dietary cholesterol. Scand J Gastroenterol 44(4): 471-477. https://doi.org/10.1080/00365520802588133

33. Gonzalez-Navarro H, Vinue A, Vila-Caballer M et al (2008) Molecular mechanisms of atherosclerosis in metabolic syndrome: role of reduced IRS2-dependent signaling. Arterioscler Thromb Vasc Biol 28(12):2187-2194. https://doi.org/10.1161/ATVBAHA. 108.175299

34. Joyce CW, Wagner EM, Basso F et al (2006) ABCA1 overexpression in the liver of LDLr-KO mice leads to accumulation of proatherogenic lipoproteins and enhanced atherosclerosis. J Biol Chem 281(44):33053-33065. https://doi.org/10.1074/jbc.M604526200

35. Zhao XY, Xiong X, Liu T et al (2018) Long noncoding RNA licensing of obesity-linked hepatic lipogenesis and NAFLD 
pathogenesis. Nat Commun 9(1):2986. https://doi.org/10.1038/ s41467-018-05383-2

36. Jin C, Henao-Mejia J, Flavell RA (2013) Innate immune receptors: key regulators of metabolic disease progression. Cell Metab 17(6): 873-882. https://doi.org/10.1016/j.cmet.2013.05.011

37. Miele L, Beale G, Patman G et al (2008) The Kruppel-like factor 6 genotype is associated with fibrosis in nonalcoholic fatty liver disease. Gastroenterology 135(1):282-291. https://doi.org/10. 1053/j.gastro.2008.04.004

Publisher's note Springer Nature remains neutral with regard to jurisdictional claims in published maps and institutional affiliations. 